\title{
XÁC ĐỊNH PHƯƠNG ÁN XÂY DỰNG HỆ THỐNG ĐO ĐẠC-BÁO CÁO-THẨM TRA CHO TÀI CHÍNH KHÍ HẬU TẠI VIẸT NAM
}

\author{
Phạm Thanh Long ${ }^{1}$, Huỳnh Thị Lan Hương ${ }^{1}$, Nguyễn Tú Anh ${ }^{1}$, \\ Vương Xuân Hòa ${ }^{1}$, Nguyễn Thị Liễu ${ }^{1}$, Đoàn Quang Trí ${ }^{2}$
}

Tóm tắt: Để đạt được muc tiêu đề ra trong đóng góp dụ kiến do quốc gia tụ quyết định, Việt Nam đang nỗ lục thu hút đầu tu tù cộng đồng quốc tế cũng nhu huy động các nguồn lục trong nước để đảm bảo cho việc thục hiện các hoạt động liên quan đến cam kết giảm nhe KNK sau năm 2020 của mình. Tuy nhiên, giám sát tài chính khí hậu vẫn là một thách thức với các quốc gia đang phát triển nói chung và Việt Nam nói riêng. Do vậy, Việt Nam cần có một hệ thống đo đạc, báo cáo và thẩm tra $(M R V)$ công khai và minh bạch về tình hình và hiệu quả sủ dụng các nguồn vốn hỗ trợ dành cho úng phó với $B Đ K H$. Tù đó xây dựng được lòng tin của các nhà tài trợ, nâng cao số lượng và hiệu quả của các dụ án khi hậu và đạt được các muc tiêu đề ra. Vì thế, bài báo này được thục hiện để cung cấp cái nhìn tổng quan và đề xuất phuơng án thiết kế hệ thống MRV đối với tài chính khí hậu cho Việt Nam. Ngoài ra, kết quả của nghiên cứu cũng đóng góp một co sở quan trọng để xây dụng một hệ thống MRV toàn diện hỗ trợ cho Việt Nam bao gồm cả tài chính khi hậu, chuyển giao công nghệ và tăng cưòng năng lực trong tưong lai.

Từ khóa: MRV, biến đổi khi hậu, công khai, minh bạch.

Ban Biên tập nhận bài: 12/07/2019 Ngày phản biện xong: 15/08/2019 Ngày đăng bài: 25/11/2019

\section{Mở đầu}

MRV đã được hình thành với mục tiêu tích hợp ba quy trình tuy độc lập nhưng lại có liên quan chặt chẽ với nhau là Đo đạc (Monitoring $M)$, Báo cáo (Reporting - $R$ ) và Thẩm tra (Verification - $V$ ) để thiết lập một căn cứ minh bạch và hiệu quả cho các hành động và hỗ trợ quá trình ra quyết định. Thuật ngữ MRV lầu đầu tiên được đưa ra đối với chính sách giảm nhẹ BĐKH trong Kế hoạch hành động Bali (2007) yêu cầu các các hành động giảm nhẹ phát thải KNK phù hợp với điều kiện quốc gia (NAMA) được hỗ trợ về công nghệ, tài chính và tăng cường năng lực cần phải đo lường được (measurable), báo cáo được (reportable) và thẩm tra được (verifiable). Các nỗ lực tiếp sau đó là để xác định cái gì cần được đo dạc, báo cáo, thẩm tra, bằng cách nào, bởi ai và để làm gì [9]. Gần đây nhất là Thoả thuận Paris

'Viện Khoa học Khi tuợng Thủy văn và Biến đổi khi hậu

Email: phamthanhlong559@gmail.com về BĐKH năm 2015 yêu cầu các bên tham gia phải xây dựng và thực hiện các đóng góp do quốc gia tự quyết định (NDC) đảm bảo tính minh bạch, chính xác, đầy đủ, so sánh được, nhất quán và không tính trùng lặp. MRV là một công cụ hiệu quả để thực hiện điều này [4]. Kể từ khi các Thỏa thuận Cancun được thông qua tại COP16 (năm 2010), MRV được xác định rõ là sẽ được áp dụng cho cả các hành động giảm nhẹ của quốc gia và các hành động giảm nhẹ được hỗ trợ. Tuy nhiên, cách MRV được vận hành vẫn còn nhiều tranh luận giữa các quốc gia phát triển và đang phát triển, đặc biệt là vấn đề $\mathrm{MRV}$ đối với các hỗ trợ về tài chính, công nghệ và tăng cường năng lực [5].

Việt Nam là một trong những quốc gia tích cực tham gia vào các hoạt động ứng phó với BĐKH. Gần đây, Chính phủ Việt Nam đã ban hành Quyết định số 2053/QĐ-TTg về Kế hoạch thực hiện Thảo thuận Paris về BĐKH (Thủ tướng Chính phủ, 2016). Một trong những nhiệm 
vụ quan trọng được đề cập trong Quyết định này là thiết lập hệ thống đo đạc, báo cáo và thẩm tra (MRV) cấp quốc gia cho các hoạt động giảm nhẹ phát thải $\mathrm{KNK}$, thích ứng với $\mathrm{BĐKH}$ và huy động nguồn lực. Ngoài ra, trong Thông báo Quốc gia lần thứ ba của Việt Nam cũng chỉ ra một số khó khăn hiện tại đối với việc xây dựng các báo cáo cho Công ước khung Liên hợp quốc về Biến đổi khí hậu (UNFCCC) trong đó có đề cập về việc chưa chính thức hình thành hệ thống MRV ở các cấp, các nghành nên khó khăn cho việc thực hiệc và thiếu cơ chế phối hợp hoạt động trong triển khai thực hiện giảm phát thải KNK [7].

Bên cạnh đó, Việt Nam đã xác định các nhu cầu tài chính để thực hiện các mục tiêu giảm nhẹ KNK mà Chính phủ đã cam kết trong Đóng góp dự kiến do quốc gia tự quyết định (iNDC) cho giai đoạn 2021-2030 [3]. Theo đó, tổng nhu cầu tài chính trong nước để thực hiện cam kết tự nguyện giảm $8 \%$ lượng phát thải KNK (so với kịch bản phát triển thông thường $(\mathrm{BAU}))$ vào năm 2030 là khoảng 3,2 tỷ USD. Để đạt được mục tiêu giảm $25 \%$ lượng phát thải KNK (so với $\mathrm{BAU}$ ) vào năm 2030, cần thêm 17,9 tỷ USD từ hỗ trợ quốc tế. Hiện tại, Việt Nam đang rà soát, cập nhật NDC và dự kiến sẽ hoàn thành vào đầu năm 2020, với nhu cầu tài chính bổ sung kết hợp với các hoạt động tăng trưởng xanh. Nguồn tài chính sẽ được huy động từ tất cả các thành phần kinh tế cũng như tối đa hóa hỗ trợ quốc tế, bao gồm hỗ trợ song phương và đa phương, để thực hiện hiệu quả các mục tiêu giảm nhẹ KNK. Tiếp đó, Chính phủ Việt Nam đã ban hành Nghị quyết số 74/NQ-CP ngày 26 tháng 8 năm 2016 về việc phê duyệt định hướng đầu tư của các chương trình mục tiêu trong giai đoạn 2016-2020, bao gồm cả Chương trình mục tiêu ứng phó với biến đổi khí hậu và tăng trưởng xanh trong giai đoạn 2016-2020. Nghị quyết đã khẳng định trong những năm tới, Việt Nam sẽ tích cực thực hiện cam kết với cộng đồng quốc tế về bảo vệ khí hậu toàn cầu, đẩy mạnh và thu hút đầu tư từ cộng đồng quốc tế để giảm lượng phát thải KNK hướng đến các hoạt động triển khai đang diễn ra liên quan đến cam kết giảm nhẹ KNK sau năm 2020, phù hợp với NDC. Nhu cầu tài chính cho việc thực hiện Chương trình mục tiêu ứng phó với $\mathrm{BĐKH}$ và tăng trưởng xanh trong giai đoạn 2016-2020 được tóm tắt trong Bảng 1.

\section{Bảng 1. Nhu cầu tài chính thực hiện Chương trình muc tiêu Quốc gia về BĐKH và Tăng trương xanh [6]}

\begin{tabular}{ccccc}
\hline $\begin{array}{c}\text { Tổng } \\
\text { kinh phí }\end{array}$ & $\begin{array}{c}\text { Hợp } \\
\text { phần }\end{array}$ & $\begin{array}{c}\text { Hợp phần } \\
\text { Tăng }\end{array}$ & $\begin{array}{c}\text { Ngân } \\
\text { sách }\end{array}$ & $\begin{array}{c}\text { ODA } \\
\text { (tỷ }\end{array}$ \\
$\begin{array}{cccc}\text { BĐKH } \\
\text { trương }\end{array}$ & $\begin{array}{c}\text { trung } \\
\text { (tỷ }\end{array}$ & $\begin{array}{c}\text { xanh } \\
\text { (ty) }\end{array}$ & $\begin{array}{c}\text { ương } \\
\text { (tỷ VND) }\end{array}$ & \\
& VND) & (tỷ VND) & (ty & \\
\hline 15,866 & 11,300 & 4,566 & 866 & 15,000 \\
\hline
\end{tabular}

Tuy nhiên, Bộ Kế hoạch và Đầu tư (Bộ KH\&ĐT) cũng chỉ ra một số thách thức khác nhau để giám sát tài chính khí hậu bao gồm: (1) các định nghĩa không nhất quán về tài chính khí hậu và các tiêu chí ứng dụng; (2) phân loại và chỉ số không nhất quán để xác định dữ liệu tài chính (ví dụ: mã ngành và mã hoạt động); (3) những thách thức để đạt được một phạm vi bảo hiểm toàn diện của các công cụ tài chính; (4) hạn chế về dữ liệu tài chính tư; và sự sắp xếp thể chế không đầy đủ, bao gồm thiếu vai trò và trách nhiệm rõ ràng, sự phối hợp giữa các tổ chức kém và thiếu các quy trình và công cụ kỹ thuật [1]. Vì vậy, Việt Nam cần có một hệ thống báo cáo và đánh giá về tình hình và hiệu quả sử dụng vốn và các hỗ trợ khác dành cho ứng phó với $\mathrm{BĐKH}$ nhằm đạt được các mục tiêu đề ra.

Vì vậy, bài báo này được thực hiện để cung cấp cái nhìn tổng quan và đề xuất phương án thiết kế hệ thống MRV đối với tài chính khí hậu cho Việt Nam. Ngoài ra, kết quả của nghiên cứu cũng đóng góp một cơ sở quan trọng để xây dựng một hệ thống MRV toàn diện hỗ trợ cho Việt Nam bao gồm cả tài chính khí hậu, chuyển giao công nghệ và tăng cường năng lực trong tương lai.

\section{Phương pháp nghiên cứu}

Nghiên cứu này được thực hiện dựa trên phương pháp tổng hợp và phân tích các tài liệu liên quan đến yêu cầu xây dựng và đảm bảo thành công cho một hệ thống MRV đối với tài 
chính khí hậu. Từ đó, dựa trên tình hình thực tế, nghiên cứu xác định và đề xuất mô hình $\mathrm{MRV}$ thích hợp cho Việt Nam.

\subsection{Khái niệm chung và các khó khăn tồn tại của MRV đối với tài chính khí}

MRV đối với tài chính khí hậu (sau đây gọi tắt là MRV tài chính) là một hệ thống MRV được đưa ra để đo đạc, báo cáo và thẩm tra các dòng tài chính và những tác động của hỗ trợ đã được cung cấp [8]. Vì vậy, một khuôn khổ MRV đối với tài chính khí hậu dài hạn sẽ giúp theo dõi được đóng góp dự kiến và việc thực hiện các đóng góp đó, giúp xây dựng lòng tin giữa các quốc gia phát triển và các quốc gia đang phát triển thông qua nâng cao tính minh bạch và cải thiện quá trình báo cáo tài chính. Bên cạnh đó, hệ thống này còn cung cấp bức tranh toàn cảnh về các dòng tài chính, xu thế, nguồn và mục đích của hỗ trợ quốc tế và trong nước cho khí hậu và từ đó nâng cao được hiệu quả hợp tác quốc tế và khuyến khích đầu tư tư nhân.

Đến nay, Kế hoạch Hành động Bali, Hiệp ước Copenhagen và Thỏa thuận Cancun đã đưa ra một số yêu cầu cơ bản đối với hệ thống MRV hỗ trợ nói chung và hệ thống MRV tài chính nói riêng. Tuy nhiên, các cơ chế và quy định hiện hành vẫn chưa xác định rõ: (1) Cái gì phải được Đo đạc: dòng tài chính và mức độ chuyển giao công nghệ mà có thể được tính vào những biện pháp can thiệp liên quan đến các hành động giảm nhẹ; (2) Cái gì phải được Báo cáo: loại hình tài chính, mục đích của các loại hình đó, phân bổ theo lĩnh vực và vùng địa lý, đóng góp của khối tư nhân và phân bổ; và (3) Cái gì phải được Thẩm tra: quy mô hỗ trợ giữa các nhà tài trợ và các nước nhận tài trợ, hiệu lực của hỗ trợ và những tác động chi phí-lợi ích.

\subsection{Các yếu tố thành công của MRV tài chính}

MRV tài chính được kỳ vọng về lâu dài sẽ trở thành một hệ thống chung cho các quốc gia tài trợ và các quốc gia nhận tài trợ. Theo đó, ngoài việc sử dụng $\mathrm{MRV}$ tài chính giành riêng cho các báo cáo quốc gia về BĐKH cho UNFCCC như các yêu cầu trong khung $\mathrm{MRV}$, các nước đang phát triển cũng sử dụng loại hình $\mathrm{MRV}$ này để báo cáo cho các nhà tài trợ như các tổ chức tài chính đa phương (ví dụ: Ngân hàng Thế giới), các cơ quan hợp tác phát triển song phương hoặc các tổ chức tài chính công và tư nhân quốc gia. Vì các yêu cầu đối với kiểm tra và báo cáo có thể thay đổi từ nhà tài trợ sang nhà tài trợ, một hệ thống MRV tài chính xuyên suốt và có tính linh động cao là cần thiết. Để đảm bảo cho một hệ thống MRV tài chính thành công các yếu tố sau cần được xem xét [8]:

- Phạm vi minh bạch (cam kết, lượng vốn phân bổ/huy động, các hành động đã được hỗ trợ, cấp vốn trong nước, tác động) phải được xác định bằng cách áp dụng các phương án thiết kế để vận hành MRV hỗ trợ;

- Tính hoàn chỉnh của các lĩnh vực và các loại thông tin;

- Tính nhất quán với các khung thời gian báo cáo hiện tại và tương lai trong khuôn khổ UNFCCC;

- Khả năng thu thập được của số liệu cho MRV;

- Khả năng so sánh được để điều phối và điều chỉnh các loại số liệu khác nhau, để so sánh và tổng hợp (và tránh tính 2 lần);

- Tính chính xác của thông tin thu thập được về hỗ trợ (đã được nhận);

- Khả năng dự báo được các hỗ trợ tài chính là đối tượng của MRV.

\subsection{Các bước co bản cho MRV hỗ trơ}

Như đã đề cập ở phần mở đầu, hiện nay mô hình sắp xếp thể chế cho MRV tài chính vẫn đang được hoàn thiện và dựa trên 3 trụ cột chính bao gồm: Kế hoạch Hành động Bali; Hiệp ước Copenhagen và Thỏa thuận Cancun. Về cơ bản một hệ thống MRV hỗ trợ sẽ bao gồm các bước chính như: (1) Bắt đầu, (2) Đo đạc, (3) Báo cáo, (4) Thẩm tra, (5) Liên tục cải thiện (Hình 1). Theo đó, cũng giống như các hệ thống MRV khác (MRV phát thải KNK, MRV giảm nhẹ KNK và $M R V$ thích ứng) $M R V$ tài chính bao gồm năm bước chính sau [8]:

- Bước 1: Bắt đầu

- Xác định mục tiêu dự định và lý giải sự cần 
thiết của hệ thống MRV tài chính như là một khuôn khổ MRV đối với tài chính khí hậu dài hạn;

- Phản ánh đóng góp dự kiến và các hành động (tùy thuộc và hỗ trợ đã nhận) trong thiết kế hệ thống MRV tài chính;

- Cân nhắc đến tài chính quốc tế khi thiết kế MRV tài chính và điều chỉnh tương ứng theo định hướng phát triển của các đàm phán quốc tế.

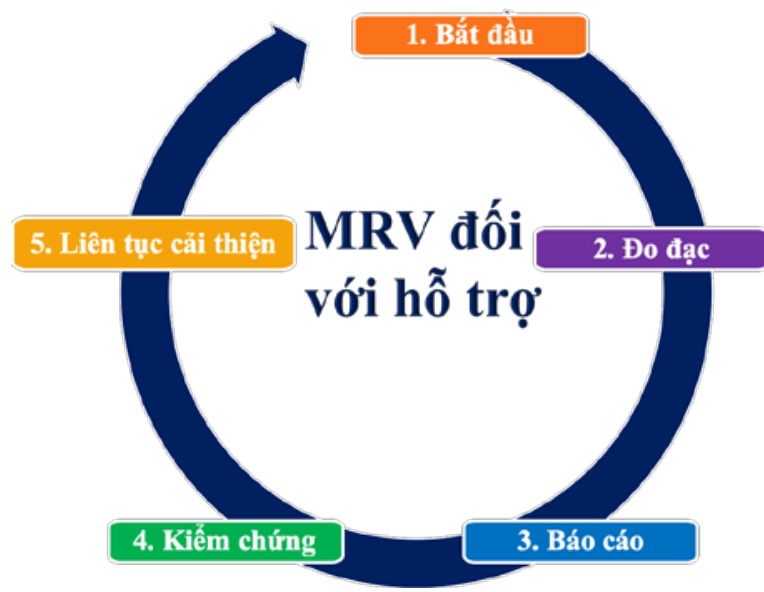

Hình 1. Các thành phần của hệ thống MRV hố trọ [8]

- Bước 2: Đo đạc: Nội dung đang được đàm phán trong khuôn khổ UNFCCC liên quan đến xác định MRV tài chính là hệ thống này cần bao trùm những gì, ví dụ:

- Dòng tài chính: từ tổ chức nào đến tổ chức nào, lượng tài chính, loại công cụ tài chính, khối tư nhân/khối chính phủ, mới/bổ sung;

- Loại hình hỗ trợ tài chính;

- Các hành động được hỗ trợ, mức độ tác động (ngành, vùng, v.v.);

- Tác động của các hành động được hỗ trợ các chỉ số định lượng/định tính.

Điểm được nhấn mạnh ở bước này là sự chuyên môn hoá của các cơ quan chính phủ liên quan và sự tham gia của lĩnh vực tư nhân.

- Bước 3: Báo cáo: Các báo cáo về tài chính khí hậu bao gồm các thông tin về:

- Loại hình tài chính (viện trợ không hoàn lại, vay ưu đãi, cổ phần, bảo lãnh, v.v.);

- Mục đích của hỗ trợ (Phân loại: giảm nhẹ/thích ứng);

- Phân bổ hỗ trợ giữa các ngành/các hoạt động, hay theo vùng địa lý;

- Cân đối với tài chính tư nhân;

- Tác động mong muốn/đã đạt;

- So sánh lượng hỗ trợ đã cam kết với lượng hỗ trợ đã giải ngân.

- Bước 4: Thẩm tra: Tiến trình thẩm tra đang được đàm phán trong khuôn khổ UNFCCC với những nội dung cơ bản sau:

- Quy mô hỗ trợ (so sánh số liệu từ bên hỗ trợ và bên nhận hỗ trợ);

- Hiệu quả của hỗ trợ (lượng giảm phát thải thực tế và/hoặc kết quả thực hiện các ưu tiên của các quốc gia đang phát triển);

- Tác động chi phí-lợi ích (ví dụ: đối với thích ứng, tăng trưởng xanh).

Thẩm tra tài chính được hiểu một cách đơn giản là sự so sánh các số liệu từ bên hỗ trợ và bên nhận hỗ trợ. Quy tắc cốt lõi của Thẩm tra tài chính (bao gồm cả đảm bảo chất lượng và quản lý chất lượng) là phải được thực hiện bởi các chuyên gia tài chính độc lập, không liên quan đến chính trị. Hiện tại, chưa có hướng dẫn về Thẩm tra tài chính khí hậu.

- Bước 5: Liên tục cải thiện: Liên tục kiểm tra và đánh giá những thế mạnh, những cơ hội, những điểm yếu và những rào cản của hệ thống hệ tại (Phân tích SWOT) cần được chú trọng thực hiện để xác định và đưa ra phương án cải thiện. Do vậy, cần giải quyết những thách thức sau:

- Rất nhiều kênh tài chính khí hậu và khả năng quan sát chúng;

- Phân biệt các kênh của các dòng tài chính;

- Năng lực không đồng nhất và các cơ chế quản lý.

Kết quả từ MRV tài chính cần được đưa ra trong bản đánh giá lại đối với các cam kết.

\section{Kết quả và thảo luận}

3.1. Phân tích thể chế MRV hỗ trọ và vai trò/trách nhiệm của các bên liên quan

\subsubsection{Co sơ của MRV hỗ trơ}

Phương án thiết kế thể chế và quy trình của MRV tài chính được xác định tuỳ thuộc vào mức độ minh bạch được kỳ vọng. Theo đó, các phương án thiết kế được xác định như sau [5]: 
- Xây dựng lòng tin giữa các quốc gia phát triển và các quốc gia đang phát triển thông qua nâng cao tính minh bạch và tính giải trình: phương án thiết kế 1;

- Đưa ra một cái nhìn tổng quan rõ ràng hơn về các dòng tài chính, xu thế, nguồn và các mục đích của hỗ trợ khí hậu quốc tế và trong nước: phương án thiết kế 2;

- Theo dõi các đóng góp dự kiến và việc thực hiện những đóng góp đó: phương án thiết kế 3;

- Xác định các thực hành tốt và cải thiện tính hiệu quả của hành động quốc tế và tạo động lực cho đầu tư từ khu vực tư nhân: phương án thiết kế 4 .

3.1.2 Mô tả các phrơng án thiết kế thể chế và vai trò/trách nhiệm của các bên liên quan

Các phương án thiết kế được xác định và tổng kết trong hình 2 [5]:

- Phương án thiết kế 1: Xác định phạm vi minh bạch dự kiến sẽ đạt được thông qua quy trình MRV là cam kết hỗ trợ quốc tế được thực hiện bởi các quốc gia phát triển, cũng như thực tế hỗ trợ được huy động và/hoặc phân bổ, sau đó và so sánh hai bên. Trọng tâm hiện tại của các cuộc đàm phán và cũng là lĩnh vực trọng tâm của các nghiên cứu trước đây phù hợp với phương án thiết kế này. Tùy chọn thiết kế này có thể được chia nhỏ thành cam kết hỗ trợ tổng hợp được thực hiện bởi các quốc gia phát triển (tức là hỗ trợ dài hạn) và cam kết hỗ trợ được thực hiện riêng bởi một quốc gia phát triển theo cam kết tài chính tập thể. Khi quy trình MRV so sánh cam kết hô̂ trợ và lượng tài chính được phân bổ/huy động, các nhà tài trợ, các nước phát triển, đóng vai trò là đơn vị báo cáo;

- Phương án thiết kế 2: Đặt phạm vi minh bạch vượt ra ngoài khía cạnh cam kết của hỗ trợ và nhằm bảo đảm tính minh bạch đối với nội dung của các hoạt động được hỗ trợ ở cấp hoạt động riêng lẻ, bao gồm các chi tiết về kênh hỗ trợ, lĩnh vực mục tiêu, loại hoạt động và khối lượng tài nguyên cung cấp cho từng hoạt động được hỗ trợ. Tương tự như Phương án thiết kế 1, các quốc gia phát triển cũng đóng vai trò là thực thể báo cáo của quy trình MRV này.

- Phương án thiết kế 3: nhằm mục đích thiết lập phạm vi minh bạch đối với lượng tài nguyên tài chính được phân bổ/huy động và phân bổ nguồn lực nhận được trong nước ở các quốc gia nhận để khám phá sự gắn kết giữa hai bên. Ở một mức độ nhất định, tùy chọn thiết kế này cho phép nhìn rộng hơn về quy trình MRV được Mỹ nêu rõ trong các tài liệu MISC. Không giống như tùy chọn thiết kế 1 và 2 , các thực thể báo cáo của tùy chọn thiết kế này bao gồm cả các quốc gia phát triển và đang phát triển.

- Phương án thiết kế 4: Nhằm đảm bảo tính minh bạch đối với số lượng hỗ trợ thực tế được phân bổ và/hoặc huy động bởi các nước phát triển và các tác động giảm thiểu được tạo ra từ các hành động được hỗ trợ, từ đó nắm bắt được sự minh bạch về đầu vào và đầu ra của hỗ trợ quốc tế. Tùy chọn thiết kế này cũng hợp nhất các yếu tố hiện đang được thảo luận riêng biệt như thành phần giảm thiểu và tài chính theo đàm phán UNFCCC và cả các nước phát triển và đang phát triển đóng vai trò là đơn vị báo cáo của thiết kế này'.

Các nội dung chi tiết và đánh giá cụ thể từng phương án thiết kế trên có thể tìm thấy trong báo cáo của IGES về "Vận hành MRV hỗ trợ" [5]. Về cơ bản, mỗi tùy chọn thiết kế cho MRV tài chính đều cho thấy cả ưu điểm và nhược điểm về khía cạnh vận hành. Liên quan đến nội dung của từng phương án thiết kế, có thể thấy phạm vi minh bạch tăng dần đồng nghĩa với yêu cầu về lượng thông tin cung cấp và độ phức tạp của thể chế để đảm bảo vận hành của các phương án tăng dần từ phương án 1 đến phương án 4 . Bên cạnh đó, nghĩa vụ kiểm tra và báo cáo của bên nhận hỗ trợ tăng dần từ phương án 1 đến 4 . Đồng thời, cần nhấn mạnh là mọi lựa chọn phương án thiết MRV tài chính đều phụ thuộc vào mức độ chi tiết và khối lượng thông tin hỗ trợ cần thiết để đảm bảo tính minh bạch. Do đó, đơn giản hoá về thủ tục và giảm chi phí vận hành của quy trình MRV là những yếu tố quan trọng để đảm bảo sự tính khả thi của một hệ thống MRV tài chính. 


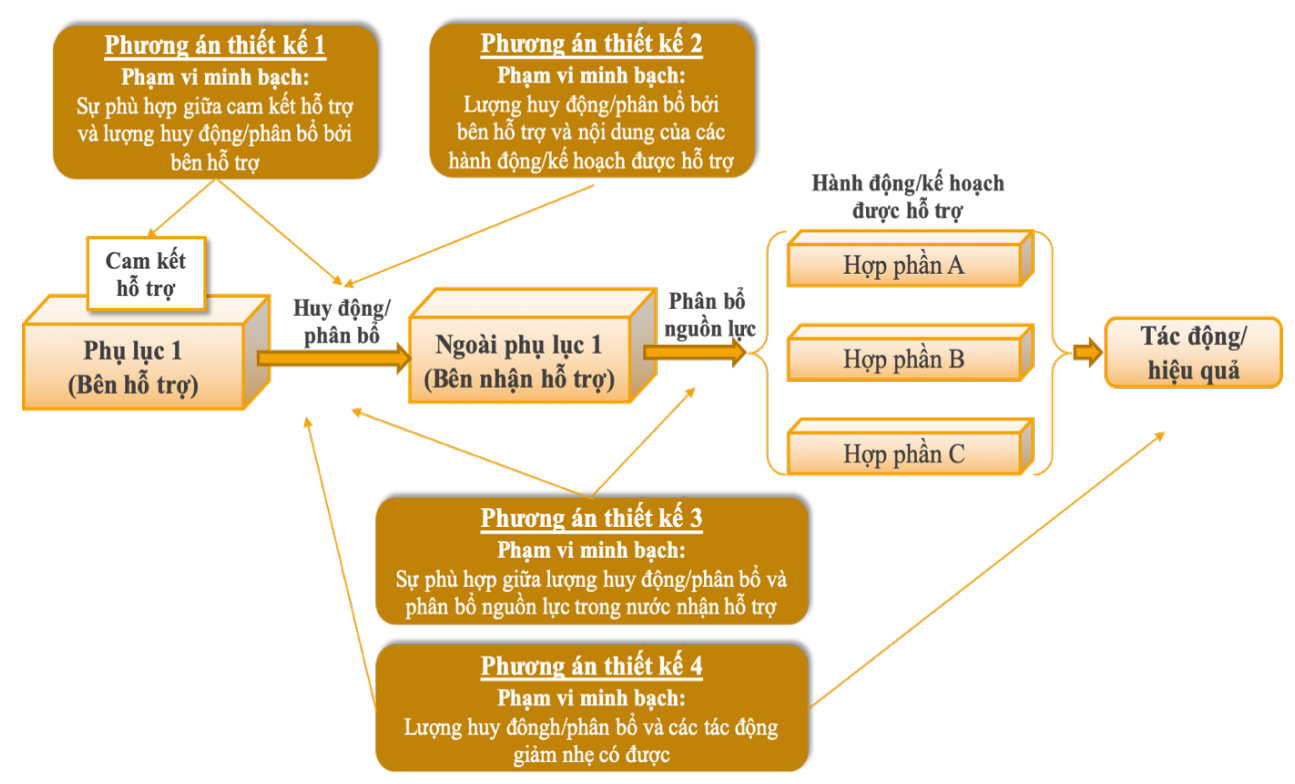

Hình 2. Các phương án thiết kế tiềm năng cho MRV tài chính [3]

\section{2. Đề xuất mô hình MRV hỗ trọ' cho Việt Nam}

Như đã đề cập ở mục 3, hiện nay chưa có lựa chọn chính thức về phương án thiết kế MRV tài chính cả ở cấp quốc tế và quốc gia. Tuy nhiên, để chuẩn bị sã̃n sàng cho vận hành hệ thống MRV tài chính trong tương lai, Việt Nam cần có một hệ thống MRV tài chính quốc gia đủ mạnh để đảm bảo cho các thông tin về nhu cầu cũng như phân phối các nguồn tài chính khí hậu cả trong nước và quốc tế chính xác và đáng tin cậy. Hình 3 thể hiện mô hình MRV quốc gia tiềm năng cho Việt Nam bao gồm MRV tài chính, MRV giảm nhẹ và $M R V$ thích ứng và hỗ trợ tài chính. Mô hình này được xây dựng dựa trên những quy định và hệ thống MRV hiện tại, theo đó các cơ quan liên quan đến hệ thống MRV tài chính như sau (Bộ KH\&ĐT, 2015; Bộ TN\&MT, Bộ TC, \& Bộ KH\&ĐT, 2013):

Đầu mối MRV hỗ trọ̣ cấp quốc gia là Bộ Kế hoạch và Đầu tu:

- Bộ KH\&ĐT chịu trách nhiệm xây dựng hướng dẫn chiến lược cho chi tiêu ứng phó với biến đổi khí hậu và lồng ghép các chính sách BĐKH trong kế hoạch phát triển kinh tế xã hội;

- Tổng hợp trình Thủ tướng Chính phủ phê duyệt danh mục các dự án liên quan đến BĐKH theo đề xuất của Bộ Tài nguyên và Môi trường (Bộ TN\&MT);

- Chủ trì, phối hợp với Bộ Tài chính, Bộ TN\&MT phân bổ và thông báo tổng mức, cơ cấu vốn cho từng dự án liên quan đến $\mathrm{BĐKH}$ cho các Bộ, ngành, địa phương (bao gồm cả dự án mở mới và dự án chuyển tiếp theo phân kỳ dự toán);

• Bộ KH\&ĐT ban hành Hướng dẫn phân loại chi tiêu cho ứng phó với BĐKH, yêu cầu tất cả các dự án liên quan tới BĐKH phải được phân loại, xác định được mục tiêu, các chỉ tiêu và các mốc thực hiện;

- Bộ KH\&ĐT chỉ đạo lập dự toán cho ứng phó BĐKH của tất cả các dự án liên quan tới biến đổi khí hậu tại các đơn vịitổ chức thực hiện thí điểm;

• Chuẩn bị Dự thảo biên bản ghi nhớ thí điểm về Ngân sách dành cho BĐKH phục vụ Báo cáo dự toán ngân sách hàng năm (ABSR);

- Bộ KH\&ĐT và Bộ TN\&MT tăng cường công tác giám sát trong suốt quá trình thực hiện dự án;

- Chuẩn bị Báo cáo Ngân sách khí hậu.

Bộ Tài chính:

- Phối hợp với Bộ KH\&ĐT tổng hợp trình Thủ tướng Chính phủ phê duyệt danh mục các dự án liên quan đến BĐKH theo đề xuất của Bộ TN\&MT;

- Chủ trì, phối hợp với Bộ KH\&ĐT, Bộ TN\&MT - cơ quan thường trực của Ủy ban quốc gia về BĐKH để xác định tổng mức vốn do Nhà tài trợ cam kết đã hòa vào ngân sách nhà nước để bố trí cho các dự án về trong dự toán ngân sách nhà nước hàng năm, trình Thủ tướng Chính phủ phê duyệt; 
- Phối hợp với Bộ TN\&MT kiểm tra tình hình thực hiện các dự án về BĐKH;

- Bộ Tài chính phối hợp các Bộ liên quan và chỉ đạo Sở tài chính tham gia chuẩn bị báo cáo tổng chi cho các dự án liên quan đến BĐKH.

Bộ Tài nguyên và Môi trường:

- Trên cơ sở đề nghị của các Bộ, ngành, địa phương, rà soát kết quả thực hiện các dự án liên quan đến $\mathrm{BĐKH}$ và năm thực hiện, phối hợp với các Bộ KH\&ĐT và Bộ Tài chính tổng hợp nhu cầu kinh phí thực hiện các dự án năm kế hoạch, trình cấp có thẩm quyền xem xét quyết định;

- Chủ trì, phối hợp với các cơ quan liên quan cung cấp cho các nhà tài trợ kế hoạch ngân sách năm cho $\mathrm{BĐKH}$ và kế hoạch phân bổ vốn chi tiết theo từng dự án;

- Chủ trì, phối hợp với Bộ KH\&ĐT, Bộ Tài chính và các Bộ, ngành liên quan kiểm tra, đánh giá tình hình thực hiện các dự án liên quan đến BĐKH, báo cáo Thủ tướng Chính phủ, Ủy ban quốc gia về $\mathrm{BĐKH}$ và thông báo cho các nhà tài trợ theo hiệp định đã ký (nếu có);

- Định kỳ 6 tháng, hàng năm tổng hợp báo cáo tình hình thực hiện các dự án BĐKH gửi Thủ tướng Chính phủ, Ủy ban Quốc gia về $\mathrm{BĐKH,}$ Bộ KH\&ĐT, Bộ Tài chính. Báo cáo 6 tháng gửi trước ngày 15 tháng 8 , báo cáo năm gửi trước ngày 30 tháng 4 năm sau;

- Chủ trì, phối hợp với Bộ KH\&ĐT, Bộ Tài chính tổng hợp kết quả thực hiện dự án liên quan đến BĐKH để báo cáo Thủ tướng Chính phủ, Ủy ban quốc gia về BĐKH và thông báo cho các nhà tài trợ theo hiệp định đã ký (nếu có).

Các Bộ, ngành và địa phương:

- Chịu trách nhiệm tổ chức thẩm định và phê duyệt dự án trong danh mục dự án được Thủ tướng Chính phủ phê duyệt đảm bảo phân kỳ dự án phù hợp với nguồn vốn thực hiện dự án được xác định hàng năm;

- Chỉ đạo chủ đầu tư và các đơn vị liên quan thực hiện các dự án được giao đúng mục đích, hiệu quả theo các quy định hiện hành;

- Đối với địa phương phải đảm bảo vốn đối ứng cần thiết từ ngân sách địa phương và các nguồn vốn huy động khác để thực hiện các nhiệm vụ chi được quy định;

- Thực hiện lồng ghép với các chương trình, dự án khác để thực hiện các dự án liên quan đến BĐKH có hiệu quả. Bố trí đủ phần vốn địa phương cho các dự án theo tiến độ đã cam kết khi trình Thủ tướng Chính phủ phê duyệt danh mục các dự án được đầu tư từ nguồn vốn giành cho BĐKH.

- Thực hiện công tác báo cáo theo quy định hiện hành về báo cáo dự án đầu tư, đồng thời báo cáo định kỳ 6 tháng, hàng năm theo hướng dẫn của Bộ TN\&MT. Báo cáo 6 tháng gửi Bộ TN\&MT trước ngày 15 tháng 7 , báo cáo năm gửi trước ngày 15 tháng 3 năm sau.

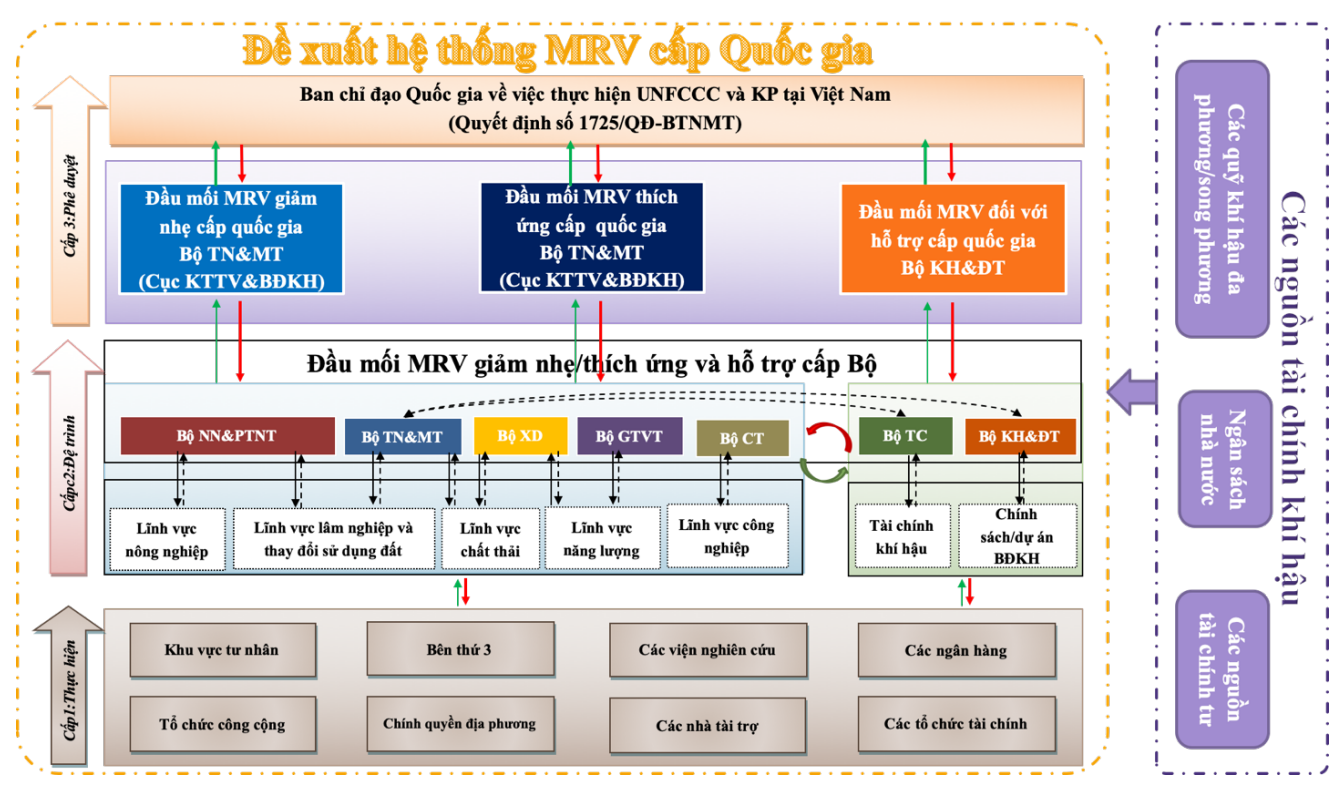

Hình 3. Đề xuất hệ thống MRV đối với hỗ trọ̆ cho Việt Nam ([8], [10], [11]) 


\section{Kết luận}

Mục tiêu của nghiên cứu này là cung cấp cái nhìn tổng quan và đề xuất phương án thiết kế hệ thống MRV đối với tài chính khí hậu cho Việt Nam. Theo đó một số chú ý đối với việc lựa chọn phương án thiết kết MRV tài chính được chỉ ra như sau:

- Do yêu cầu về kiểm tra và báo cáo có thể thay đổi tuỳ vào nhà tài trợ, hệ thống $M R V$ cần phải xuyên suốt và có tính linh động cao;

- Các yếu tố đảm bảo cho sự thành công của hệ thống MRV bao gồm: tính minh bạch, tính hoàn chỉnh, tính nhất quán, khả năng thu thập số liệu, khả năng so sánh chéo và tính chính xác;

- Có bốn phương án thiết kế MRV tài chính đã được đưa ra. Liên quan đến nội dung của từng phương án thiết kế thì phạm vi minh bạch tăng dần đồng nghĩa với yêu cầu về lượng thông tin cung cấp và độ phức tạp của thể chế để đảm bảo vận hành của các phương án tăng dần từ phương án 1 đến phương án 4 . Bên cạnh đó, nghĩa vụ kiểm tra và báo cáo của bên nhận hỗ trợ tăng dần từ phương án 1 đến 4 ;

- Về cơ bản, mỗi tùy chọn thiết kế cho MRV tài chính đều cho thấy cả ưu điểm và nhược điểm về khía cạnh vận hành. Đồng thời, cần nhấn mạnh là mọi lựa chọn phương án thiết MRV tài chính đều phụ thuộc vào mức độ chi tiết và khối lượng thông tin hỗ trợ cần thiết để đảm bảo tính minh bạch. Do đó, đơn giản hoá về thủ tục và giảm chi phí vận hành của quy trình $\mathrm{MRV}$ là những yếu tố quan trọng để đảm bảo sự tính khả thi của một hệ thống MRV tài chính.

Bên cạnh đó, nghiên cứu cũng đã đề xuất phương án thiết kế cho hệ thống MRV tài chính cấp quốc gia cho Việt Nam. Đầu mối của MRV tài chính là Bộ KH\&ĐT, chịu trách nhiệm đưa ra chiến lược và hướng dẫn chi tiêu ứng phó với $\mathrm{BĐKH}$ và lồng ghép các chính sách $\mathrm{BĐKH}$ trong kế hoạch phát triển kinh tế xã hội của quốc gia; Bộ Tài chính và Bộ TN\&MT cần phối hợp chặt chẽ với Bộ KH\&ĐT trong tổng hợp các hoạt động ứng phó với $\mathrm{BĐKH,} \mathrm{kinh} \mathrm{phí} \mathrm{tương}$ ứng cần thiết, thông tin cho các nhà tài trợ và kiểm tra, giám sát việc thực hiện các dự án; Các Bộ, nghành và địa phương chịu trách nhiệm thẩm định, phê duyệt dự án, chỉ đạo, tiến hành các hoạt động và chuẩn bị nguồn lực cần thiết đảm bảo thực hiện các dự án, thực hiện báo cáo theo quy định hiện hành.

Kết quả của nghiên cứu đã đóng góp một cơ sở quan trọng để xây dựng một hệ thống MRV toàn diện hỗ trợ cho Việt Nam bao gồm cả tài chính khí hậu, chuyển giao công nghệ và tăng cường năng lực trong tương lai.

Lời cảm ơn: Nhóm tác giả xin chân thành cảm ơn đề tài nghiên cứu khoa học và phát triển công nghệ cấp Nhà nuoớc "Nghiên cứu đề xuất hệ thống giám sát - báo cáo - thẩm định (MRV) các hoạt động ưng phó với biến đổi khí hậu ở Việt Nam”, mã số BĐKH.32/16-20 đã hỗ trọ để thực hiện bài báo này.

\section{Tài liệu tham khảo}

1. Bộ KH\&ĐT (2015), Ngân sách cho Úng phó với Biến đổi khi hậu ở Việt Nam: Đầu Tu Thông Minh Vì Tương Lai Bền Vũng. Hà Nội.

2. Bộ TN\&MT, Bộ TC, \& Bộ KH\&ĐT (2013), Thông tu liên tịch số 03/2013/TTLT-BTNMTBTC-BĐKH ngày 05/03/2013 về Hướng dẫn co chế quản lý nguồn vốn Chuơng trình Hỗ trợ úng phó với biến đổi khi hậu. Hà Nội: Bộ Tài Nguyên và Môi Trường, Bộ Tài Chính và Bộ Kế hoạch và Đầu tur.

3. Government of Viet Nam (2015), Intended Nationally Determined Contribution of Viet Nam, Submission to UNFCCC. Ha Noi. Retrieved from http://www4.unfccc.int/submissions/INDC/Published Documents/Viet Nam/1/VIETNAM'S INDC.pdf

4. Herold, A., Böttcher, H., (2018), Accounting of the land-use sector in nationally determined 


\title{
BÀI BÁO KHOA HỌC
}

contributions (NDCs) under the Paris Agreement. Bonn: Deutsche Gesellschaft für Internationale Zusammenarbeit (GIZ) GmbH. Retrieved from https://www.transparencypartnership.net/system/files/document/Guide Accounting of land-use sector in NDCs\%28vf\%29_20181010.pdf.

5. IGES (2011), Operationalising MRV of Support: Analysis of Finance, Technology and Capacity Building Support. Kanagawa. Retrieved from https://pub.iges.or.jp/system/files/publication_documents/pub/policyreport/2439/operationalising_mrv_of_support.pdf

6. MONRE (2017), The Second Biennial Updated Report of Vietnam to the United Nations Framework Convention on Climate Change. Ha Noi, Viet Nam: Ministry of Natural Resources and Environment (MONRE), Viet Nam.

7. MONRE (2019), The Third National Communication of VietNam to the United Nation Framewwork Convention on Climate Change. Ha Noi: Ministry of Natural Resources and Environment (MONRE), Viet Nam.

8. Pang, Y., Thistlethwaite, G., Watterson, J., Okamura, S., Harries, J., Varma, A., Cornu, E. Le. (2018), MRV - Đo đạc, Báo cáo, Thẩm tra: Các xây dụng các hệ thống MRV quốc gia (Draft 4.1). Eschborn: Deutsche Gesellschaft für Internationale Zusammenarbeit (GIZ) GmbH.

9. Singh, N., Finnegan, J., Levin, K., (2016), MRV 101: Understanding Measurement, Reporting, and Verification of Climate change Mitigation. Washington, DC. Retrieved from http://www.wri.org/sites/default/files/MRV_101_0.pdf

10. Thủ tướng Chính phủ (2016), Quyết định số 2053/QĐ-TTg ngày 28/10/2016 của Thủ tuớng Chinh phủ về việc ban hành Kế hoạch thực hiện Thảo thuân Paris về biến đổi khí hậu. Hà Nội: Việt Nam.

\section{GUIDELINES FOR DESIGNING MONITORING, REPORTING AND VERIFICATION SYSTEM OF CLIMATE FINANCE IN VIET NAM \\ Long Thanh Pham ${ }^{1}$, Huong Lan Thi Huynh', Tu Anh Nguyen', Hoa Xuan Vuong ${ }^{1}$, Doan Quang Tri ${ }^{2}$}

${ }^{1}$ Viet Nam Institute of Meteorology, Hydrology and Climate change

${ }^{2}$ Viet Nam Meteorological and Hydrological Administration

\begin{abstract}
To achieve goals outlined in the Intended Nationally Determined Contribution, Viet Nam is making efforts to attract investment from the international community as well as mobilizing domestic resources to ensure the implementation of activities related to its commitment to GHG mitigation after 2020. However, the country has to face various challenges regarding climate finance monitoring. Therefore, it is necessary to have a transparent monitoring, reporting and verification $(M R V)$ system to track the status and effectiveness in the application of financial sources to support climate change response activities. This system can either enhance the trust of donors or increase either the quantity and efficiency of climate projects facilitating the achievement of the set goals. Therefore, this paper aims to provide an overview and propose a proper design of MRV system for climate finance in Vietnam. Moreover, the results of this study also contribute an important basis for developing a comprehensive MRV system for support of Vietnam, including climate finance, technology transfer and capacity building in the future.
\end{abstract}

Keywords: MRV, Climate change, Transperancy. 